\title{
Alcohol Sensing through Photonic Crystal Fiber at Different Temperature
}

\author{
Etu Podder, Rayhan Habib Jibon, Md. Bellal Hossain, Abdullah Al-Mamun Bulbul, \\ Sagor Biswas, Md. Anamul Kabir
}

Electronics and Communication Engineering (ECE) Discipline, Khulna University, Khulna, Bangladesh

Email:e2.120926@gmail.com

How to cite this paper: Podder, E., Jibon, R.H., Hossain, Md.B., Al-Mamun Bulbul, A., Biswas, S. and Kabir, Md.A. (2018) Alcohol Sensing through Photonic Crystal Fiber at Different Temperature. Optics and Photonics Journal, 8, 309-316.

https://doi.org/10.4236/opj.2018.810026

Received: September 12, 2018

Accepted: October 19, 2018

Published: October 22, 2018

Copyright $\odot 2018$ by authors and Scientific Research Publishing Inc. This work is licensed under the Creative Commons Attribution International License (CC BY 4.0).

http://creativecommons.org/licenses/by/4.0/

\begin{abstract}
This paper presents the investigation of relative sensitivity profile of Alcohol through Photonic Crystal fiber at different temperature. Here, 15\%, 40\%, $60 \%, 75 \%$ of Ethyl Alcohol-water mixture is inserted through the core of Photonic crystal fiber at temperature like $20^{\circ} \mathrm{C}, 25^{\circ} \mathrm{C}$ and $30^{\circ} \mathrm{C}$. COMSOL Multiphysics is used as simulation software and the simulation process is done at wavelength range $600 \mathrm{~nm}$ to $1600 \mathrm{~nm}$. From this work, the relative sensitivity is obtained approximately $44,44.59,44.85,45$ in percentage at temperature $20^{\circ} \mathrm{C}, 42,44.2,44.8,44.9$ in percentage at temperature $25^{\circ} \mathrm{C}$, and $42,43.8,44.5,44.85$ in percentage at temperature $30^{\circ} \mathrm{C}$ for $15 \%, 40 \%, 60 \%$, $75 \%$ of Ethyl Alcohol-water mixture at wavelength $1500 \mathrm{~nm}$ respectively. Again, higher sensitivity is achieved when this sensor is operated at lower temperature.
\end{abstract}

\section{Keywords}

Photonic Crystal Fiber, Relative Sensitivity, COMSOL Multiphysics

\section{Introduction}

Initially in 1966, Optical fiber technology was developed for telecommunication applications. After that this technology got a huge positive feedback among the researchers. Very soon optical fibers were seen to expand its application area like sensing field. The growths of photonic crystal fibers (PCFs) with their significant optical properties have confirmed the prospective benefits of optical fibers in chemical and biological sensing [1] [2] [3]. The outstanding characteristics of these micro structured fibers such as small size, freedom of design, and relative compatibility make them stand out for sensing applications [4] [5] [6]. Where in conventional fibers, designing is not so easy, core size is limited, material selec- 
tion is tough etc. Moreover, these limitations on the geometry hamper the flexibility in recognizing fiber properties such as dispersion [2] [7], confinement loss [8] [9], birefringence [2] [9], relative sensitivity [10] etc. PCF provides us with long distance light propagation that was not possible previously. Light propagation characteristics can be controlled by adjusting the air holes in the core and cladding region. A lot of research studies are already done in the fields of optical communications [10] [11], nonlinear optics [11] and sensing [12] [13] [14].

Sensitivity vastly depends on refractive index of material. The higher the refractive index of a material, the higher the sensitivity. For this reason, Sensing material with lower refractive index is very tough, but with blessing of PCF lower index materials can also be sensed [13] [14] [15].

Water and alcohols are considered as the major analytes for these types of applications because they account for the immense majority of biological or chemical solutions [16] [17]. We need to know how much alcohol is mixed water within any drinking liquid as drinking large amount of alcohol is harmful for human body. Alcohols are also used to make different biomedical solution so sensing alcohol is a great issue. Sensing properties of alcohol highly depend on its concentration as well as in which temperature it is measured [18] [19] [20].

In this research work, we proposed a simple hexagonal PCF structure where ethyl alcohol-water mixture is inserted through the core region. In order to realize the sensitivity profile of ethyl alcohol-water mixture, we have varied the concentration of ethyl alcohol and also we have varied the operating temperature to investigate the sensitivity profile.

\section{Materials and Methods}

In this thesis, we have designed a hexagonal PCF structure in COMSOL Multiphysics (version-5).

Silica glass is used as core material which is surrounded by three layers of air holes with diameter, $\mathrm{d} 1=1.6 \mathrm{um}$ and pitch, $\Lambda=2.1 \mathrm{um}$. Air holes are used to guide the light propagation through the core. In the core area, 6 holes with diameter, $\mathrm{d}=1.2 \mathrm{um}$ and another 7 holes with diameter $0.8 \mathrm{um}$ is filled with different concentration of Ethyl Alcohol at different temperature. A perfectly matched layer (PML) of $0.7 \mathrm{um}$ is used. The designed hexagonal PCF structure is shown in Figure 1.

In this work, we have taken different mixture of Ethyl alcohol-water at different temperature and then we have investigated the relative sensitivity of ethyl alcohol at different temperature at wavelength range from $600 \mathrm{~nm}$ to $1600 \mathrm{~nm}$. Refractive index of Ethyl Alcohol-Water Mixture changes with its concentration as well as its operating temperature. Tables 1-3 show the refractive index for different concentration of Ethyl Alcohol-Water mixture and at temperature $20^{\circ} \mathrm{C}, 25^{\circ} \mathrm{C}, 30^{\circ} \mathrm{C}$ respectively.

The relative sensitivity can be calculated by using the below equation [14] [15] [16]: 


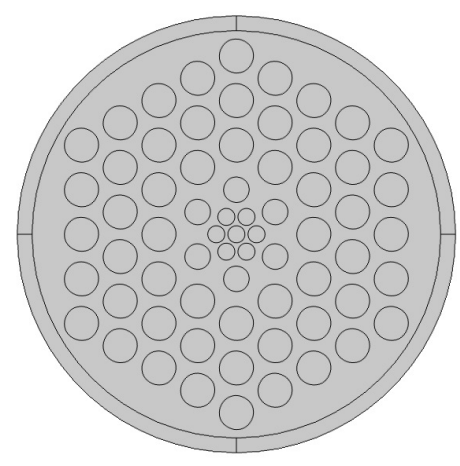

(a)

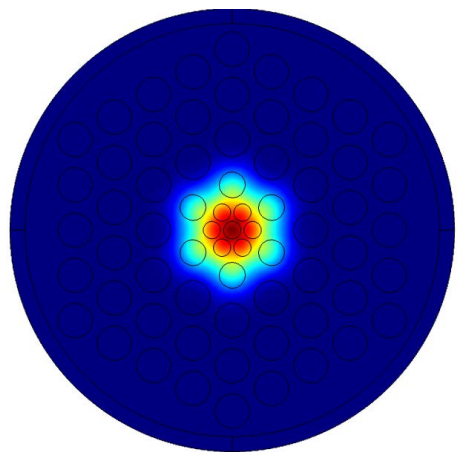

(b)

Figure 1. Proposed hexagonal PCF structure in COMSOL Multiphysics: (a) Transverse geometry and (b) Fundamental mode field of the PCF.

Table 1. Refractive index of ethyl alcohol-water mixtures at $20^{\circ} \mathrm{C}$.

\begin{tabular}{cc}
\hline Ethyl Alcohol amount (\%) & Refractive Index at temperature $20^{\circ} \mathrm{C}$ \\
\hline 15 & 1.34361 \\
40 & 1.35855 \\
60 & 1.36336 \\
75 & 1.36472 \\
\hline
\end{tabular}

Table 2. Refractive index of ethyl alcohol-water mixtures at $25^{\circ} \mathrm{C}$.

\begin{tabular}{cc}
\hline Ethyl Alcohol amount (\%) & Refractive Index at temperature $25^{\circ} \mathrm{C}$ \\
\hline 15 & 1.34298 \\
40 & 1.35705 \\
60 & 1.36185 \\
75 & 1.36334 \\
\hline
\end{tabular}

Table 3. Refractive index of ethyl alcohol-water mixtures at $30^{\circ} \mathrm{C}$.

\begin{tabular}{cc}
\hline Ethyl Alcohol amount (\%) & Refractive Index at temperature $30^{\circ} \mathrm{C}$ \\
\hline 15 & 1.34188 \\
40 & 1.3558 \\
60 & 1.35992 \\
75 & 1.36114 \\
\hline
\end{tabular}

$$
r=\frac{n_{r}}{n_{e f f}} f
$$

Where $n_{r}$ is the refractive index of sensed material and $n_{\text {eff }}$ is the modal effective refractive index which is obtained from Comsol Multiphysics simulation. Again, $\mathrm{f}$ is the power ration in percentage which $\mathrm{f}$ can be obtained from Comsol Multiphysics simulation directly using the rule given below [14] [15] [16]: 


$$
f=\frac{\int_{\text {sample }} \operatorname{Re}\left(E_{x} H_{y}-E_{y} H_{x}\right) \mathrm{d} x \mathrm{~d} y}{\int_{\text {total }} \operatorname{Re}\left(E_{x} H_{y}-E_{y} H_{x}\right) \mathrm{d} x \mathrm{~d} y} \times 100
$$

Here, $E_{x}, E_{y}$ and $H_{x}, H_{y}$ are the transverse electric field and magnetic field in $x$ and $y$ axies respectively. Then putting the values of $n_{r}, n_{\text {eff }}$ and $f$ in MATLAB we can get relative sensitivity curve with respect to wavelength.

\section{Simulation Results}

We have got the simulated result for different concentration of Ethyl Alcohol-Water mixtures as well as for different temperature. Then the simulated result is inserted into MATLAB and then the relative sensitivity curves are obtained with respect to different wavelength. The sensitivity curves of Ethyl Alcohol water mixture for different concentration at temperature $20^{\circ} \mathrm{C}, 25^{\circ} \mathrm{C}, 30^{\circ} \mathrm{C}$ are shown for wavelength range from $600 \mathrm{~nm}$ to $1600 \mathrm{~nm}$. A tuning laser can be used to have light of different wavelength. The relative sensitivity profile for different concentration of Ethyl Alcohol at temperature $20^{\circ} \mathrm{C}$ is shown in Figure 2.

For $20^{\circ} \mathrm{C}$ temperature, the relative sensitivity is increasing with increasing amount of Ethyl Alcohol water mixture as the refractive index goes higher with increasing amount of Ethyl Alcohol. Again, the relative sensitivity is increasing with increasing wavelength. The relative sensitivity is obtained approximately 37.5, 40.6, 41.5, 42 in percentage at wavelength $1200 \mathrm{~nm}$ and 44,44.59, 44.85, 45 in percentage at wavelength $1500 \mathrm{~nm}$ when $15 \%, 40 \%, 60 \%, 75 \%$ of Ethyl Alcohol-water mixture is inserted through the core region respectively.

We performed the same procedure to investigate the relative sensitivity profile at temperature $25^{\circ} \mathrm{C}$ and it is shown in Figure 3.

For $25^{\circ} \mathrm{C}$ temperature, the relative sensitivity is also increasing with increasing amount of Ethyl Alcohol water mixture as the refractive index goes higher with increasing amount of Ethyl Alcohol.

Again, the relative sensitivity is also increasing with increasing wavelength. The relative sensitivity is obtained approximately $37,40,41.5,41.8$ in percentage at wavelength $1200 \mathrm{~nm}$ and 42, 44.2, 44.8, 44.9 in percentage at wavelength 1500 $\mathrm{nm}$ when sensing liquid is $15 \%, 40 \%, 60 \%, 75 \%$ of Ethyl Alcohol-water mixture respectively.

Again, we performed similar experiment to investigate the relative sensitivity profile at temperature $30^{\circ} \mathrm{C}$ and it is shown in Figure 4.

For $30^{\circ} \mathrm{C}$ temperature, the relative sensitivity is also increasing with increasing amount of Ethyl Alcohol water mixture as the refractive index goes higher with increasing amount of Ethyl Alcohol. Again, the relative sensitivity is increasing with increasing wavelength. The relative sensitivity is obtained approximately 36.9, 40, 41, 41.2 in percentage at wavelength $1200 \mathrm{~nm}$ and 42, 43.8, 44.5, 44.85 in percentage at wavelength $1500 \mathrm{~nm}$ for 15\%, 40\%, 60\%, 75\% of Ethyl Alcohol-water mixture respectively. 


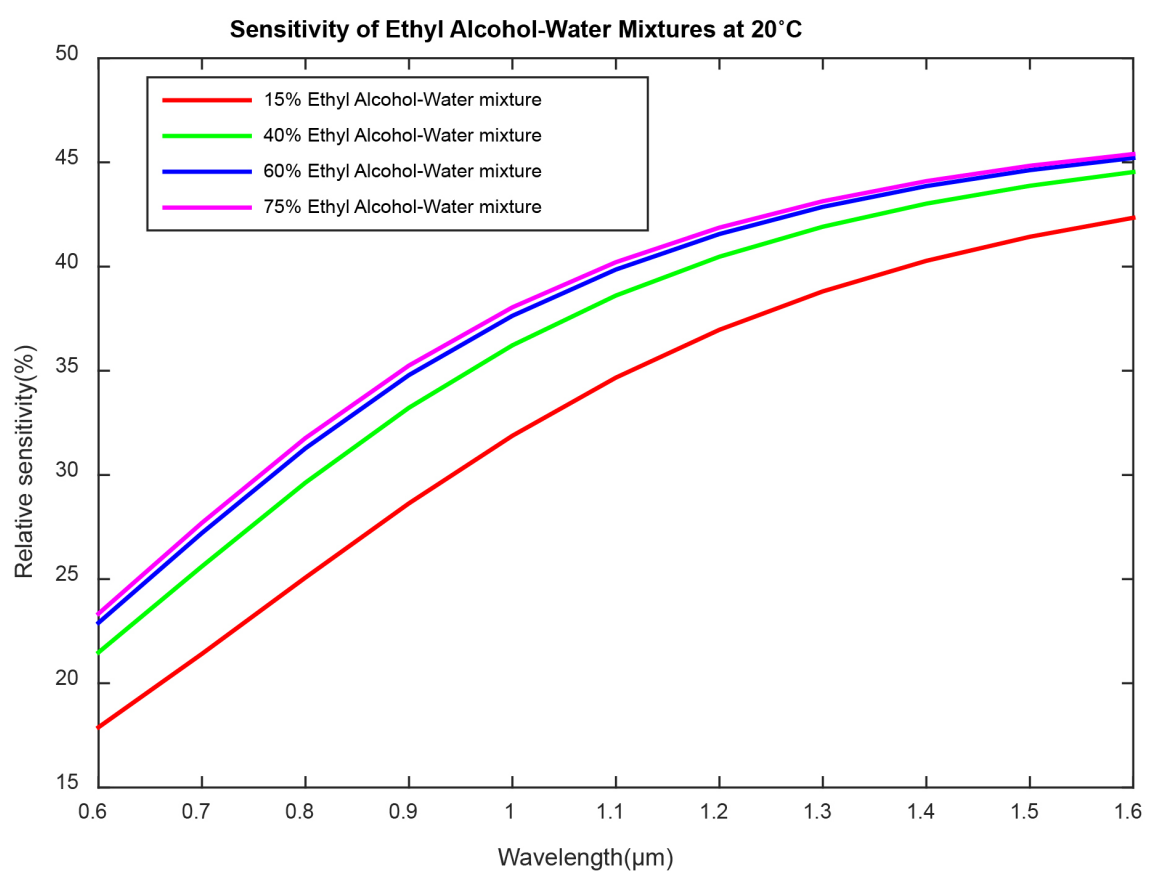

Figure 2. The sensitivity profile of Ethyl Alcohol water mixture for different concentration at temperature $20^{\circ} \mathrm{C}$.

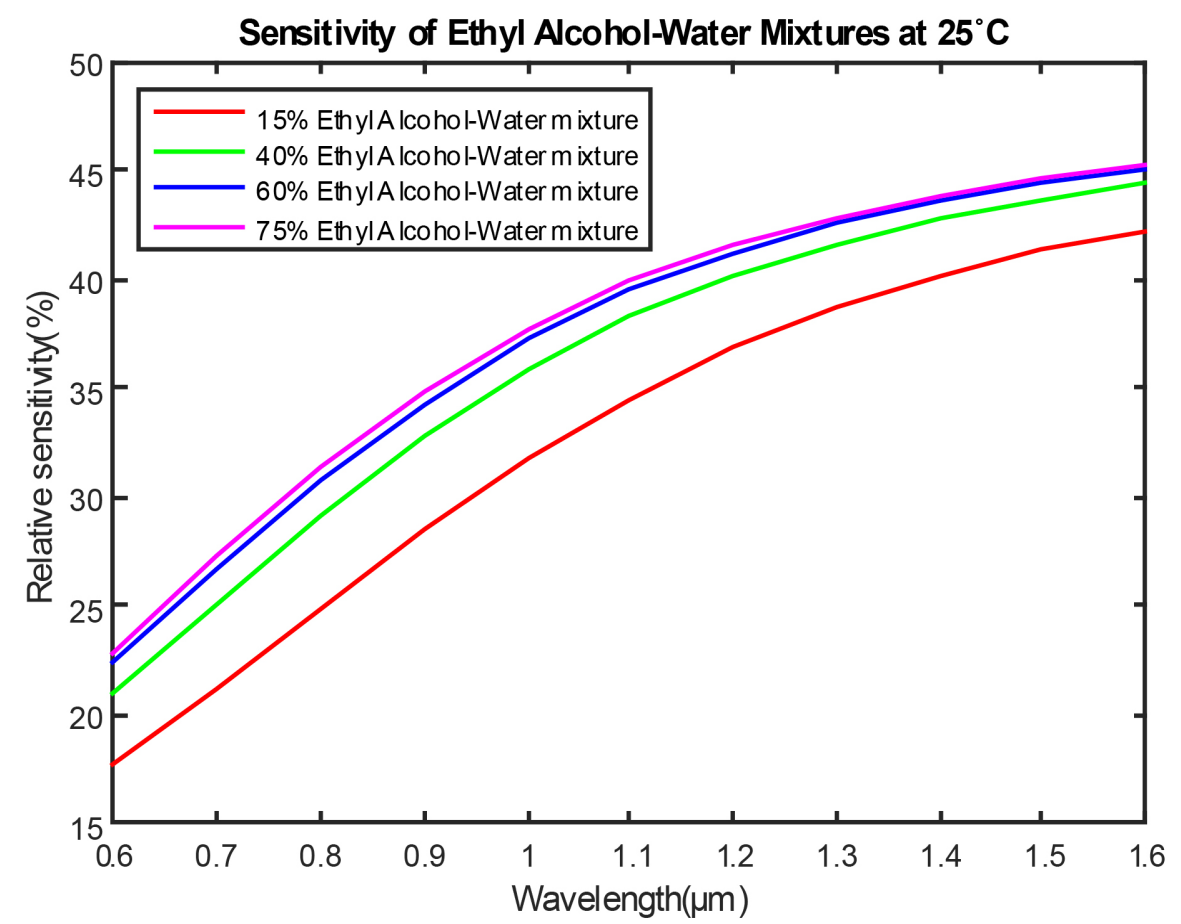

Figure 3. The sensitivity profile of Ethyl Alcohol water mixture for different concentration at temperature $25^{\circ} \mathrm{C}$.

Then we have taken 15\% of Ethyl Alcohol-water mixture as sensing liquid and then we performed sensing operation at different temperature and the relative sensitivity profile for different temperature is shown in Figure 5. 


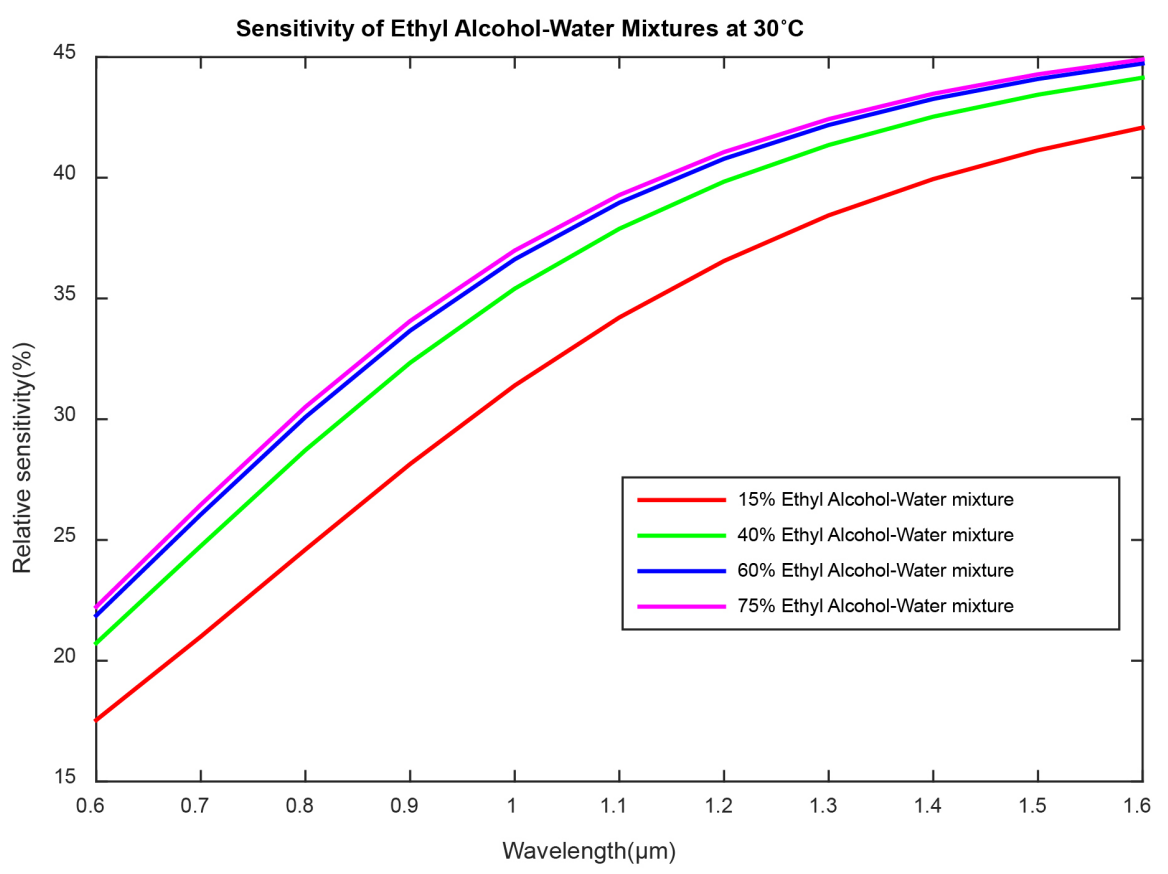

Figure 4. The sensitivity profile of Ethyl Alcohol water mixture for different concentration at temperature $30^{\circ} \mathrm{C}$.

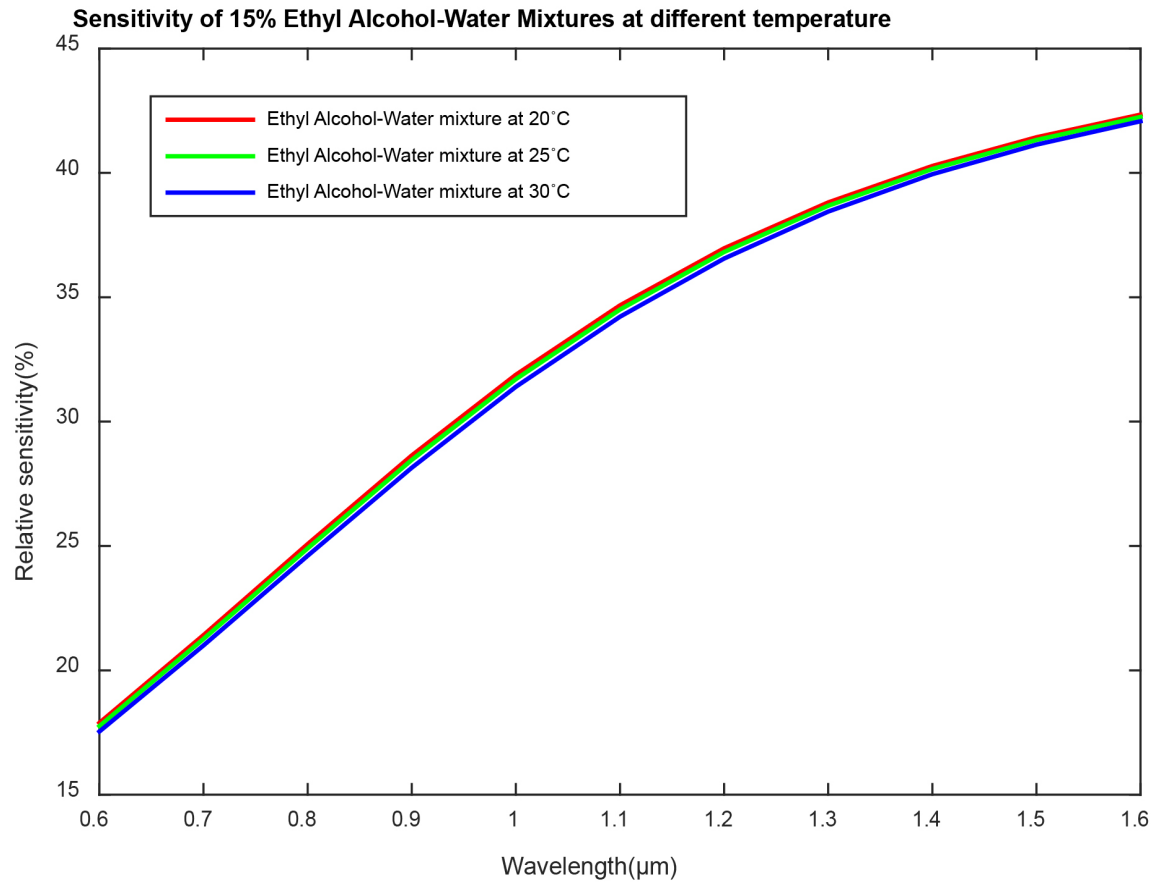

Figure 5. The Relative sensitivity profile of 15\% Ethyl Alcohol water mixture at different temperature.

The relative sensitivity profile is increasing with increasing wavelength as like before. Again, it is decreasing with increasing temperature which means higher sensitivity will be achieved when we will operate this sensor at lower temperature. The relative sensitivity is obtained approximately $37,36.5,36$ in percentage 
at wavelength $1200 \mathrm{~nm}$ and 42, 41.5, 41 in percentage at wavelength $1500 \mathrm{~nm}$ when sensing liquid is $15 \%$ of Ethyl Alcohol-water mixture at temperature $20^{\circ} \mathrm{C}$, $25^{\circ} \mathrm{C}, 30^{\circ} \mathrm{C}$ respectively.

\section{Conclusion}

In this research work, a simple hexagonal photonic crystal fiber (PCF) sensor has been designed in Comsol Multiphysics to sense Ethyl Alcohol. The main goal of this research is to investigate the relative sensitivity profile by varying the concentration of liquid as well as operating temperature. At wavelength 1500 $\mathrm{nm}$, the relative sensitivity is obtained approximately $44,44.59,44.85,45$ in percentage at temperature $20^{\circ} \mathrm{C}, 42,44.2,44.8,44.9$ in percentage at temperature $25^{\circ} \mathrm{C}, 42,43.8,44.5,44.85$ in percentage at temperature $30^{\circ} \mathrm{C}$ for $15 \%, 40 \%, 60 \%$, $75 \%$ of Ethyl Alcohol-water mixture respectively. Again, lower sensitivity is observed when this sensor is operated at higher temperature.

\section{Conflicts of Interest}

The authors declare no conflicts of interest regarding the publication of this paper.

\section{References}

[1] Pinto, A.M. and Lopez-Amo, M. (2012) Photonic Crystal Fibers for Sensing Applications. Journal of Sensors, 2012, Article ID: 598178. https://doi.org/10.1155/2012/598178

[2] Chen, D., Vincent Tse, M.L. and Tam, H.Y. (2010) Optical Properties of Photonic Crystal Fibers with a Fiber Core of Arrays of Subwavelength Circular Air Holes: Birefringence and Dispersion. Progress in Electromagnetics Research, 105, 193-212. https://doi.org/10.2528/PIER10042706

[3] Olyaee, S., Seifouri, M., Nikoosohbat, A. and Abadi, M.S.E. (2015) Low Nonlinear Effects Index-Guiding Nanostructured Photonic Crystal Fiber. International Journal of Chemical, Nuclear, Materials and Metallurgical Engineering, 9, 253-257.

[4] Geerthana, S., Raja, A.S. and Sundar, D.S. (2015) Design and Optimization of Photonic Crystal Fiber with Improved Optical Characteristics. Journal of Nonlinear Optical Physics \& Materials, 24, Article ID: 1550051. https://doi.org/10.1142/S0218863515500514

[5] Hossain, M.B., Podder, E. and Adhikary, A. (2018) Optimized Hexagonal Photonic Crystal Fibre Sensor for Glucose Sensing. Advances in Research, 13, 1-7.

[6] Kim, S., Lee, Y.S., Lee, C.G., Jung, Y. and Oh, K. (2015) Hybrid Square-Lattice Photonic Crystal Fiber with Broadband Single-Mode Operation, High Birefringence, and Normal Dispersion. Journal of the Optical Society of Korea, 19, 449-455. https://doi.org/10.3807/JOSK.2015.19.5.449

[7] Wu, B.Q., Lu, Y., Hao, C.J., Duan, L.C., Luan, N.N., Zhao, Z.Q. and Yao, J.Q. (2013) Hollow-Core Photonic Crystal Fiber Based on $\mathrm{C}_{2} \mathrm{H}_{2}$ and $\mathrm{NH}_{3}$ Gas Sensor. In: $A p$ plied Mechanics and Materials, Vol. 411, Trans Tech Publications, Zürich, 1577-1580.

[8] Priya, K.R., Raja, A.S. and Sundar, D.S. (2016) Design of a Dual-Core Liquid-Filled Photonic Crystal Fiber Coupler and Analysis of Its Optical Characteristics. Journal 
of Optical technology, 83, 569-573. https://doi.org/10.1364/JOT.83.000569

[9] Hossain, M.B., Kabir, M.A., Bulbul, A.A.M., Podder, E. and Hossen, M.K. (2017) Optical Parameters Analysis of Photonic Crystal Fiber with Rectangular Lattice Geometry. Journal of Scientific Research \& Reports, 17, 1-8.

[10] Hossain, M.B., Bulbul, A.A.M., Mukit, M.A. and Podder, E. (2017) Analysis of Optical Properties for Square, Circular and Hexagonal Photonic Crystal Fiber. Optics and Photonics Journal, 7, 235-243. https://doi.org/10.4236/opj.2017.711021

[11] Ademgil, H. (2014) Highly Sensitive Octagonal Photonic Crystal Fiber Based Sensor. Optik-International Journal for Light and Electron Optics, 125, 6274-6278. https://doi.org/10.1016/j.ijleo.2014.08.018

[12] Akowuah, E.K., Gorman, T., Ademgil, H., Haxha, S., Robinson, G.K. and Oliver, J.V. (2012) Numerical Analysis of a Photonic Crystal Fiber for Biosensing Applications. IEEE Journal of Quantum Electronics, 48, 1403-1410. https://doi.org/10.1109/JQE.2012.2213803

[13] Pinto, A.M.R., Baptista, J.M., Santos, J.L., Lopez-Amo, M. and Frazão, O. (2012) Micro-Displacement Sensor Based on a Hollow-Core Photonic Crystal Fiber. Sensors, 12, 17497-17503. https://doi.org/10.3390/s121217497

[14] Liu, S., Wang, Y., Hou, M., Guo, J., Li, Z. and Lu, P. (2013) Anti-Resonant Reflecting Guidance in Alcohol-Filled Hollow Core Photonic Crystal Fiber for Sensing Applications. Optics Express, 21, 31690-31697.

https://doi.org/10.1364/OE.21.031690

[15] Cubillas, A.M., Unterkofler, S., Euser, T.G., Etzold, B.J., Jones, A.C., Sadler, P.J. and Russell, P.S.J. (2013) Photonic Crystal Fibres for Chemical Sensing and Photochemistry. Chemical Society Reviews, 42, 8629-8648. https://doi.org/10.1039/c3cs60128e

[16] Yu, Y., Li, X., Hong, X., Deng, Y., Song, K., Geng, Y. and Tong, W. (2010) Some Features of the Photonic Crystal Fiber Temperature Sensor with Liquid Ethanol Filling. Optics Express, 18, 15383-15388. https://doi.org/10.1364/OE.18.015383

[17] Hao, R. and Sun, G. (2015) Design of Photonic Crystal Fiber with Large Negative Dispersion and High Nonlinearity. Optik-International Journal for Light and Electron Optics, 126, 3353-3356. https://doi.org/10.1016/j.ijleo.2015.07.135

[18] Guo, S., Wu, F., Albin, S., Tai, H. and Rogowski, R.S. (2004) Loss and Dispersion Analysis of Microstructured Fibers by Finite-Difference Method. Optics Express, 12, 3341-3352. https://doi.org/10.1364/OPEX.12.003341

[19] Luo, M., Liu, Y.G., Wang, Z., Han, T., Wu, Z., Guo, J. and Huang, W. (2013) Twin-Resonance-Coupling and High Sensitivity Sensing Characteristics of a Selectively Fluid-Filled Microstructured Optical Fiber. Optics Express, 21, 30911-30917. https://doi.org/10.1364/OE.21.030911

[20] Lee, H.W., Schmidt, M.A., Uebel, P., Tyagi, H., Joly, N.Y., Scharrer, M. and Russell, P.S.J. (2011) Optofluidic Refractive-Index Sensor in Step-Index Fiber with Parallel Hollow Micro-Channel. Optics Express, 19, 8200-8207.

https://doi.org/10.1364/OE.19.008200 